Article

\title{
Second Law Analysis of Ciliary Pumping Transport in an Inclined Channel Coated with Carreau Fluid under a Magnetic Field
}

\author{
Sufian Munawar ${ }^{1}$ and Najma Saleem ${ }^{2, *(1)}$ \\ 1 Department of Quantitative Methods, College of Business Administration, Imam Abdulrahman Bin Faisal \\ University, P.O. Box 1982, Dammam 34212, Saudi Arabia; smunawar@iau.edu.sa \\ 2 Department of Mathematics and Natural Sciences, Prince Mohammad Bin Fahd University, Khobar 31952, \\ Saudi Arabia \\ * Correspondence: nsaleem@pmu.edu.sa
}

Received: 20 January 2020; Accepted: 25 February 2020; Published: 5 March 2020

\begin{abstract}
A complete thermal analysis is performed for the propulsion of cilia in an inclined channel. Coating around the channel walls is provided by a Carreau fluid under a uniform magnetic field. Uniformly grown cilia produce propulsive metachronal waves by moving in a coordinated rhythm along the channel surface and adapt an elliptic path along the direction of flow. Using lubrication approximations, the governing equations, formulated in the wave frame of reference, are solved by the perturbation method. Validation of the analytic solution is provided by computing the solution numerically with the shooting method. This study is concerned with the parametric consequences on pertinent flow and heat transfer quantities, such as streamlines, velocity profile, temperature profile, entropy lines and the Bejan number. The results reveal that large cilia propel the axial velocity near the channel wall but put hindrance to the axial velocity and the temperature profile in the central part of the channel. The entropy production in the channel reduces for large cilia and a high Hartmann number.
\end{abstract}

Keywords: second-law analysis; magnetic field; inclined channel; Carreau fluid; ciliary motion

\section{Introduction}

In various physiological and biological fields, the study of cilia-assisted propulsive fluid flows has grabbed tremendous attention from researchers all over the globe. Cilia are small chunk-like structures present on the outer side or inner side of a variety of biological organisms and organs. These tiny extremity organelles drive fluid flow and provide support to organisms in passing through the fluid medium. There are numerous cilia on a structure and they are smaller than flagella in size. The combined motion of cilia produces rhythmic waves that allow the body to move in the fluid. These cilia can be found in the lungs [1], providing support in smooth breathing and keeping airways clear by preventing the entrance of dust and mucus. Also, in the covering of the female fallopian tube [2,3], they assist fertilization by pushing the eggs. Moreover, in male efferent ductules [4], they support the sperm in reaching their ultimate endpoint, prevent their accumulation and clear any obstruction in their way. Similarly, the progress of spinal fluid through the brain is also supported by cilia. Primary cilia play an essential role in sensory neurons and are considered a sensory tool for the cell [5]. Furthermore, there are numerous applications of cilia found in the brain, eye, ears, kidneys and retina, etc. Due to the practical significance of cilia in human life, this area of research has received immense attention from numerous current investigators, and they studied cilia movement under various flow and heat transfer situations. In this regard, the propulsive movement of cells inside a Newtonian fluid was 
investigated by Brennen [6]. Qiu et al. [7] established that in non-Newtonian fluid flow under a low Reynolds number, cilia and flagella produce reciprocal motions to keep the microorganisms moving. In a study on egg transport in the fallopian tube and ovum, it was observed by Eytan and Elad [8] that fluid motion in the fallopian tube occurs because of myometrial contractions. Interested readers are referred to these recent studies on cilia [9-12] under various flow situations.

Several physiological fluids, such as plasma and blood, are considered as hydromagnetic fluids in their composition. Therefore, hydromagnetic fluids have extensive applications in physiology and are thus studied widely by numerous researchers in the field. In this regard, Stud et al. [13] investigated the pumping of blood flow and heat transfer in the presence of a moving magnetic field. Another study on hydromagnetic physiological flow was conducted by Maqbool et al. [14], dealing with Jeffrey fluid flow induced by cilia beats. A well-known result regarding the magnetic Hartmann number was reported by Hayat et al. [15], where they showed that increasing the Hartman number enhances the velocity near the boundary wall but decreases it at the central part. Ramesh et al. [16] studied couple stress fluid flow propelled by cilia pumping under an applied magnetic field. Some other researchers [17-20] have also considered the effect of an external magnetic field on different physiological fluids under various physical situations.

The second law of thermodynamics associated with the production of entropy has great involvement in physiological fluid flows. For instance, metabolism is considered as an important process in generating energy in living creatures. Human beings take in the diet and flush out the waste materials in the form of breathing, perspiration, urination and feces. Therefore, the body's overall entropy tends to increase and may interrupt blood and urine flow and food digestion, etc. Catabolism is a kind of metabolism which breaks down the compound molecules into small molecules and generates entropy. Also, the local entropy level in the human body drops down when the human body extracts the chemical energy from food in order to sustain life. Since the phenomenon of entropy has substantial applications in biological fluids, it has gained the attention of many researchers. A fundamental study depicting the entropy generation in four separate heat transfer situations was done by Bejan [21]. In another study, Bejan [22] reported a method of minimizing the total entropy of a heat transfer process. It was also discovered that heat transfer and fluid friction are the two main reasons for entropy production in any heat transfer situation. The work has further been extended by several researchers [23-29] who have investigated the phenomenon of entropy in various flow and heat transfer configurations. However, very little attention has been given to biological fluid flows. In this regard, entropy production was analyzed for a peristaltic pumping flow in a contracting tube by Souidi et al. [30]. Akbar [31] extended the work by adding the effect of a magnetic field on peristaltic flow inside a tube. Munawar et al. [32] and Saleem [33] further studied the effect of space-dependent viscosity on entropy production.

In the light of the above-mentioned literature survey, in this article we intend to investigate second-law analysis of a physiological fluid flow inside an inclined channel assisted with cilia. A uniform magnetic field is applied in the perpendicular direction to resist the Carreau fluid flow. The flow in the symmetric channel is produced due to the metachronal strokes of the cilia which generate waves at the wall surface. The two main causes of entropy production are studied-the fluid friction irreversibility and the heat transfer irreversibility. The governing equations are modeled using lubrication approximations and analytic series solutions are obtained using regular perturbation. The results are compared with a numerical shooting method and a brief graphical analysis has been made in the discussion section.

\section{Mathematical Formulation}

Consider an incompressible Carreau fluid flow passing through a two-dimensional inclined symmetric channel. The flow is pumped by the periodic beating of cilia at a constant speed $c$ which produces metachronal waves in the parallel direction to the flow. A uniform magnetic field of intensity $B_{0}$ is enforced across the direction of flow, ignoring the electric field effect. Therefore, assuming a low 
magnetic Reynolds number, the Lorentz force reduces $J \times B=-\sigma B_{0}^{2}(\bar{U}, 0,0)$. The channel walls are kept at a constant surface temperature of $T_{1}$. Assuming the $X$-axis is parallel to the channel wall and the $\hat{Y}$-axis is perpendicular to the channel surface, the channel surface contains ciliated structures described by the following function:

$$
\bar{Y}=\eta(\bar{X}, t)=\dot{H}=\left[a+a \varepsilon \cos \left(\frac{2 \pi}{\lambda}(\bar{X}-c t)\right)\right]
$$

The cilia tips are assumed to be obeying an elliptical motion pattern and are positioned uprightly at

$$
\bar{X}=\phi(\bar{X}, t)=X_{0}+a \varepsilon \alpha \sin \left(\frac{2 \pi}{\lambda}(\bar{X}-c t)\right)
$$

where $a$ is mean channel width, $\alpha$ is the eccentricity of elliptic path, $\varepsilon$ is the cilia length parameter, $H$ is the half channel width, $t$ is the time variable, $\lambda$ is the wavelength and $X_{0}$ is the local position of the cilia. Assuming no slip at the ciliated boundary, the movements of the cilia tips are explained by the following velocity components:

$$
\begin{aligned}
& \hat{U}_{0}=\left(\frac{\partial \bar{X}}{\partial t}\right)_{X_{0}}=\frac{-\left(\frac{2 \pi}{\lambda}\right) \operatorname{acc\alpha cos}\left(\frac{2 \pi}{\lambda}(\bar{X}-c t)\right)}{1-\left(\frac{2 \pi}{\lambda}\right) \operatorname{ac\alpha } \alpha \cos \left(\frac{2 \pi}{\lambda}(\bar{X}-c t)\right)} \\
& \hat{V}_{0}=\left(\frac{\partial \bar{Y}}{\partial t}\right)_{X_{0}}=\frac{-\left(\frac{2 \pi}{\lambda}\right) \operatorname{acc} \alpha \sin \left(\frac{2 \pi}{\lambda}(\bar{X}-c t)\right)}{1-\left(\frac{2 \pi}{\lambda}\right) \operatorname{ac} \alpha \sin \left(\frac{2 \pi}{\lambda}(\bar{X}-c t)\right)}
\end{aligned}
$$

In the laboratory frame, the laws of the conservation of mass, momentum and energy under the above assumptions take the following forms:

$$
\begin{gathered}
\frac{\partial \bar{U}}{\partial \bar{X}}+\frac{\partial \bar{V}}{\partial \bar{Y}}=0 \\
\rho\left(\frac{\partial \bar{U}}{\partial t}+\bar{U} \frac{\partial \bar{U}}{\partial \bar{X}}+\bar{V} \frac{\partial \bar{U}}{\partial \bar{Y}}\right)=\frac{-\partial \bar{P}}{\partial \bar{X}}+\frac{\partial \bar{S}_{\overline{X X}}}{\partial \bar{X}}+\frac{\partial \bar{S}_{\overline{X Y}}}{\partial \bar{Y}}-\sigma B_{0}^{2} \bar{U}+\rho g \sin (\xi) \\
\rho\left(\frac{\partial \bar{V}}{\partial t}+\bar{U} \frac{\partial \bar{V}}{\partial \bar{X}}+\bar{V} \frac{\partial \bar{V}}{\partial \bar{Y}}\right)=\frac{-\partial \bar{P}}{\partial \bar{Y}}+\frac{\partial \bar{S}_{\overline{X Y}}}{\partial \bar{X}}+\frac{\partial \bar{S}_{\overline{Y Y}}}{\partial \bar{Y}}-\rho g \cos (\xi) \\
\rho C_{P}\left(\frac{\partial}{\partial t}+\bar{U} \frac{\partial}{\partial \bar{X}}+\bar{V} \frac{\partial}{\partial \bar{Y}}\right) \bar{T}=\kappa\left(\frac{\partial^{2} \bar{T}}{\partial \bar{X}^{2}}+\frac{\partial^{2} \bar{T}}{\partial \bar{Y}^{2}}\right)+\bar{S}_{\overline{X X}} \frac{\partial \bar{U}}{\partial \bar{X}}+\bar{S}_{\bar{X} Y}\left(\frac{\partial \bar{U}}{\partial \bar{Y}}+\frac{\partial \bar{V}}{\partial \bar{X}}\right)+\bar{S}_{\overline{Y Y}} \frac{\partial \bar{V}}{\partial \bar{Y}}
\end{gathered}
$$

where $\rho$ is the fluid density, $P$ is the pressure, $\xi$ is the inclination angle, $C_{p}$ is the specific heat at constant pressure, $B_{0}$ is the constant magnetic field, $\sigma$ is the electrical conductivity, $\kappa$ is the thermal conductivity and $T$ is the fluid temperature. The extra stress tensor for the Carreau fluid can be found in literature [34-36] and is given as:

$$
\begin{gathered}
\bar{S}=-\left[\mu_{0}\left(1+(\Gamma \dot{\gamma})^{2}\right)^{\frac{n-1}{2}}\right] \overline{\dot{\gamma}} \\
\text { where } \overline{\dot{\gamma}}=\sqrt{\frac{1}{2} \sum_{i} \sum_{j} \overline{\dot{\gamma}}_{i j} \overline{\dot{\gamma}}_{j i}}=\sqrt{\frac{1}{2} \Pi}
\end{gathered}
$$

where $\mu_{0}$ is the zero-shear rate viscosity, $n$ is the dimensionless power-law index, $\Gamma$ is the time constant and $\Pi$ is the second invariant strain tensor. For $n=1$ or $\Gamma=0$, Equation (9) depicts the viscous fluid model. 
One can shift the above flow model in wave frame $(\bar{x}, \bar{y})$ by using the following transformations:

$$
\bar{x}=\bar{X}-c t, \bar{y}=\bar{Y}, \bar{u}=\bar{U}-c, \bar{v}=\bar{V}, \bar{p}(\hat{x}, \hat{y})=\bar{P}(\bar{X}, \bar{Y}, t)
$$

Further introducing non-dimensional quantities as

$$
\left.\begin{array}{r}
x=\frac{\bar{x}}{\lambda}, y=\frac{\bar{y}}{a}, u=\frac{\bar{u}}{c}, v=\frac{\lambda \bar{v}}{a c}, \beta=\frac{a}{\lambda}, h=\frac{\bar{h}}{a}, t=\frac{c \bar{t}}{a}, p=\frac{a^{2} \bar{p}}{\mu c \lambda}, \theta=\frac{T-T_{0}}{T_{1}-T_{0}}, S=\frac{a}{\mu_{0} c} \bar{S} \\
\mathfrak{R}=\frac{\rho a c}{\mu_{0}}, W e^{2}=\frac{\Gamma c}{a}, F r=\frac{c^{2}}{g a}, M=\sqrt{\frac{\sigma}{\mu_{0}}} B_{0} a, \operatorname{Pr} \frac{\rho v C_{P}}{\kappa}, E c=\frac{c^{2}}{C_{P}\left(T_{1}-T_{0}\right)}, B r=E c \operatorname{Pr}
\end{array}\right\}
$$

Using Equations (11)-(12) into Equations (5)-(10), one gets

$$
\begin{gathered}
\beta\left(\frac{\partial u}{\partial x}+\frac{\partial v}{\partial y}\right)=0 \\
\mathfrak{R} \beta\left(u \frac{\partial u}{\partial x}+v \frac{\partial u}{\partial y}\right)=\frac{-\partial p}{\partial x}-\beta^{2} \frac{\partial S_{x x}}{\partial x}-\frac{\partial S_{x y}}{\partial y}-M^{2}(u+1)+\frac{\mathfrak{R}}{F r} \sin (\xi) \\
\mathfrak{R} \beta^{3}\left(u \frac{\partial v}{\partial x}+v \frac{\partial v}{\partial y}\right)=\frac{-\partial p}{\partial y}-\beta^{3} \frac{\partial S_{x y}}{\partial x}-\beta \frac{\partial S_{y y}}{\partial y}+\frac{\beta^{2} \mathfrak{R}}{F r} \cos (\xi) \\
\mathfrak{R} \beta\left(u \frac{\partial \theta}{\partial x}+v \frac{\partial \theta}{\partial y}\right)=\frac{1}{\operatorname{Pr}}\left(\beta^{2} \frac{\partial^{2} \theta}{\partial x^{2}}+\frac{\partial^{2} \theta}{\partial y^{2}}\right)+E c\left(\begin{array}{c}
\beta S_{x x} \frac{\partial u}{\partial x}+S_{x y}\left(\beta \frac{\partial v}{\partial x}+\frac{\partial u}{\partial y}\right) \\
+S_{y y} \beta \frac{\partial v}{\partial y}
\end{array}\right)
\end{gathered}
$$

where

$$
\begin{gathered}
S_{x x}=-2\left[1+\frac{n-1}{2} W e^{2} \dot{\vartheta}^{2}\right] \frac{\partial u}{\partial x} \\
S_{x y}=-\left[1+\frac{n-1}{2} W e^{2} \dot{\gamma}^{2}\right]\left(\frac{\partial u}{\partial y}+\beta^{2} \frac{\partial v}{\partial x}\right) \\
S_{y y}=-2 \beta\left[1+\frac{n-1}{2} W e^{2} \dot{\gamma}^{2}\right] \frac{\partial v}{\partial y} \\
\dot{\gamma}=\left[2 \beta^{2}\left(\frac{\partial u}{\partial x}\right)^{2}+\left(\frac{\partial u}{\partial y}+\beta^{2} \frac{\partial v}{\partial x}\right)+2 \beta^{2}\left(\frac{\partial v}{\partial y}\right)^{2}\right]^{1 / 2}
\end{gathered}
$$

where $p$ is the dimensionless fluid pressure, $(u, v)$ are the velocity components in $(x, y)$ directions, $\mathfrak{R}$ is the Reynolds number, We is the Weissenberg number, $M$ is the Hartmann number, $\beta$ is the wave number, $F r$ is the Froude number, $P r$ is the Prandtl number, $E c$ is the Eckert number and $B r$ is the Brinkman number.

Employing lubrication approximations in Equations (14)-(20), one gets

$$
\begin{gathered}
\frac{\partial p}{\partial x}=\frac{\partial}{\partial y}\left\{\left(\frac{\partial u}{\partial y}\right)+\frac{n-1}{2} W e^{2}\left(\frac{\partial u}{\partial y}\right)^{3}\right\}-M^{2}(u+1)+\frac{\mathfrak{R}}{F r} \sin (\xi) \\
\frac{\partial p}{\partial y}=0 \\
\frac{\partial^{2} \theta}{\partial y^{2}}=-B r\left[\left(\frac{\partial u}{\partial y}\right)^{2}+\frac{n-1}{2} W e^{2}\left(\frac{\partial u}{\partial y}\right)^{4}\right]
\end{gathered}
$$

subject to the boundary conditions

$$
\frac{\partial u}{\partial y}=0, \frac{\partial \theta}{\partial y}=0 \text { at } y=0,
$$




$$
u=-1-\frac{2 \pi \alpha \varepsilon \beta \cos (2 \pi x)}{1-2 \pi \alpha \varepsilon \beta \cos (2 \pi x)}, \theta=1 \text { at } y=h=1+\varepsilon \cos (2 \pi x)
$$

The pressure rise per wavelength is calculated as:

$$
\Delta P_{\lambda}=\int_{0}^{1}\left(\frac{d p}{d x}\right) d x
$$

The dimensionless mean flow rates in the laboratory and wave frames are respectively given by:

$$
Q=1+F, F=\int_{0}^{h} u(y) d y
$$

\section{Perturbation Solution}

To get the solutions of Equations (21)-(23), along with boundary conditions (24)-(25), the perturbation series solution is obtained. Expanding the series of flow and heat transfer quantities by considering $W e^{2}$ as the perturbation parameter as

$$
\begin{aligned}
u & =u_{0}+W e^{2} u_{1}+O\left(W e^{4}\right) \\
\frac{d p}{d x} & =\frac{d p_{0}}{d x}+W e^{2} \frac{d p_{1}}{d x}+O\left(W e^{4}\right) \\
\theta & =\theta_{0}+W e^{2} \theta_{1}+O\left(W e^{4}\right) \\
F & =F_{0}+W e^{2} F_{1}+O\left(W e^{4}\right)
\end{aligned}
$$

Using the above series in Equations (21)-(23), we get the following zero and first order systems of differential equations:

3.1. Zeroth Order System

$$
\begin{gathered}
\frac{\partial p_{0}}{\partial x}=\frac{\partial^{2} u_{0}}{\partial y^{2}}-M^{2}\left(u_{0}+1\right)+\frac{\mathfrak{R}}{F r} \sin (\xi) \\
\frac{\partial p_{0}}{\partial y}=0 \\
\frac{\partial^{2} \theta_{0}}{\partial y^{2}}=-B r\left(\frac{\partial u_{0}}{\partial y}\right)^{2} \\
\frac{\partial u_{0}}{\partial y}=0, \frac{\partial \theta_{0}}{\partial y}=0 a t y=0 \\
u_{0}=-1-\frac{2 \pi \varepsilon \alpha \beta \cos (2 \pi x)}{1-2 \pi \varepsilon \alpha \beta \cos (2 \pi x)}, \theta_{0}=1 \text { aty }=h
\end{gathered}
$$

3.2. First Order System

$$
\begin{gathered}
\frac{\partial p_{1}}{\partial x}=\frac{\partial^{2} u_{1}}{\partial y^{2}}+\frac{n-1}{2} \frac{\partial}{\partial y}\left[\left(\frac{\partial u_{0}}{\partial y}\right)^{3}\right]-M^{2} u_{1} \\
\frac{\partial p_{1}}{\partial y}=0
\end{gathered}
$$




$$
\begin{gathered}
\frac{\partial^{2} \theta_{1}}{\partial y^{2}}=-B r\left[\frac{n-1}{2}\left(\frac{\partial u_{0}}{\partial y}\right)^{4}+2 \frac{\partial u_{0}}{\partial y} \frac{\partial u_{1}}{\partial y}\right] \\
\frac{\partial u_{1}}{\partial y}=0, \frac{\partial \theta_{1}}{\partial y}=0 \text { at } y=0 \\
u_{1}=0, \theta_{1}=0 \text { at } y=h
\end{gathered}
$$

Equations (32)-(41) are solved directly using the "DSolve" command of the symbolic computational software Mathematica. The solution expressions are suppressed here for simplicity. The pressure rise per metachronal wavelength is found by the numerical integration of Equation (29). The current solution by the perturbation method has been verified by solving Equations (21)-(25) by a numerical shooting method. The results for the wall skin friction $\mathrm{u}^{\prime}(h)$ obtained by both methods are reported in Table 1. The table indicates an acceptable match between analytical and numerical solutions.

Table 1. Numerical values for wall skin friction obtained by analytical and numerical methods when $Q=2, \alpha=\varepsilon=0.2, \beta=x=0.5, W e=0.01, M=0.8$ are fixed.

\begin{tabular}{ccc}
\hline $\boldsymbol{n}$ & $\mathbf{u}^{\prime}(\boldsymbol{h})$ (Analytic) & $\mathbf{u}^{\prime}(\boldsymbol{h})$ (Numerical) \\
\hline 0 & -12.885 & -12.868 \\
0.2 & -12.876 & -12.866 \\
0.4 & -12.867 & -12.860 \\
0.6 & -12.859 & -12.848 \\
0.8 & -12.854 & -12.846 \\
\hline
\end{tabular}

\section{Entropy Analysis}

It is a well-established fact that the entropy in a system is produced due to two reasons- - heat transfer irreversibility and fluid frictional irreversibility. In the literature (see for instance $[37,38]$ ), the expression of total volumetric local rate of entropy generation is stated as:

$$
S_{\text {gen }}^{\prime \prime \prime}=\frac{k}{T_{0}^{2}}(\nabla T)^{2}+\frac{\mu_{0}}{T_{0}}[S . \nabla V]
$$

Using dimensionless quantities (12) and lubrication approximations, one can find the total entropy generation number $\left(N_{G}\right)$ after dividing by characteristic entropy $\left(S_{G 0}\right)$ as:

$$
N_{G}=\tau\left(\frac{\partial \theta}{\partial y}\right)^{2}+B r\left\{\left(\frac{\partial u}{\partial y}\right)^{2}+W e^{2} \frac{n-1}{2}\left(\frac{\partial u}{\partial y}\right)^{4}\right\}
$$

where $\tau=\Delta T / T_{0}$ is the dimensionless temperature difference (assuming $\tau=1$ ). In Equation (43), the first term is the source of irreversibility due to heat transfer and the second term with Brinkman number $\mathrm{Br}$ appears due to the fluid friction irreversibility. Introducing the Bejan number $\mathrm{Be}$ as:

$$
B e=\frac{1}{1+\Phi}
$$

where $\Phi=\operatorname{Br}\left\{\left(\frac{\partial u}{\partial y}\right)^{2}+W e^{2} \frac{n-1}{2}\left(\frac{\partial u}{\partial y}\right)^{4}\right\} / \tau\left(\frac{\partial \theta}{\partial y}\right)^{2}$ is the irreversibility distribution ratio. The Bejan number is considered as a helpful parameter in order to distinguish the dominancy of irreversibilities. The value of the Bejan number $B e$ is constrained in $[0,1]$. If the Bejan number is greater than half, the dominancy of heat transfer irreversibility is reflected over fluid friction irreversibility. If $B e$ is less than half, it depicts the dominancy of fluid friction irreversibility. 


\section{Results and Discussion}

In this section, a brief graphical analysis of the results is presented for various parameters of interest on the flow and heat transfer quantities through several figures. Figure 1 demonstrates the effects of cilia length parameter $(\varepsilon)$ on the velocity profile. From the figure, it is observed that the velocity decreases in the center of the channel and at $y=0.58$ (roughly), a point of infection occurs and the velocity increases as the cilia length increases. From Figure 2, it is noted that the large value of We generates more resistance to the axial velocity in the center of the channel, but near the edge the axial velocity accelerates. Figure 3 indicates that the fluid velocity becomes flatter with an increase in $M$ in the channel center, which is due to the ability of Lorentz force to hinder the flow. However, an entirely reversed conduct is observed near the ciliated channel wall where the velocity increases as the Hartmann number increases. This phenomenon is very common in channel flows and occurs to maintain a constant flow rate across the channel. A three-dimensional velocity profile is drawn in Figure 4 against $x$ and $y$ coordinates. It indicates that the fluid velocity is high in the contracted part of the channel and lower down in the expanded region, which is the expected result. Figure 5 shows a slight increase in pressure rise per wavelength in the pumping zone as eccentricity parameter $(\alpha)$ decreases but causes a slight drop in the augmented pumping zone. Figure 6 shows that an increase in $\varepsilon$ manifests a strong acceleration on pressure rise per metachronal wavelength in the pumping area. However, the same values of $\alpha$ have entirely the opposite behavior in an augmented pumping region. Further, it is seen in Figure 7 that an increase in Hartmann number $M$ improves the pressure rise in the pumping and free pumping zone, whereas, in the augmented pumping region, higher values of $M$ lessen the pressure rise.

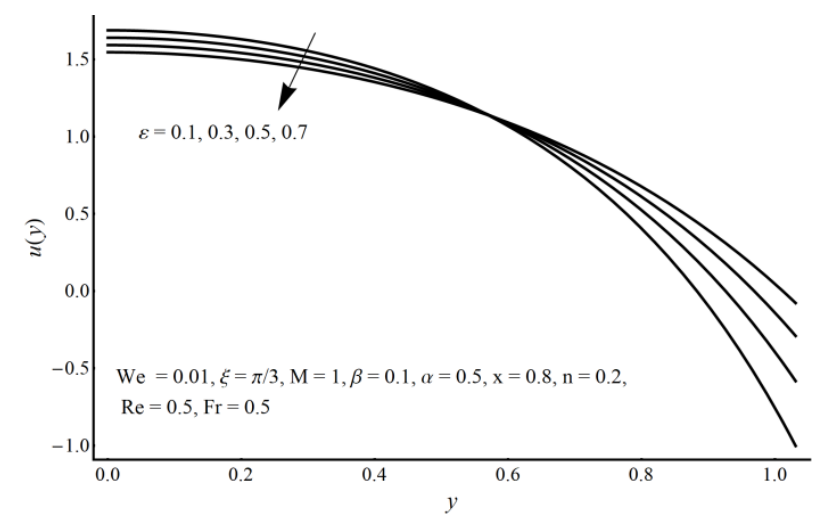

Figure 1. The velocity profile for different values of variable $\varepsilon$.

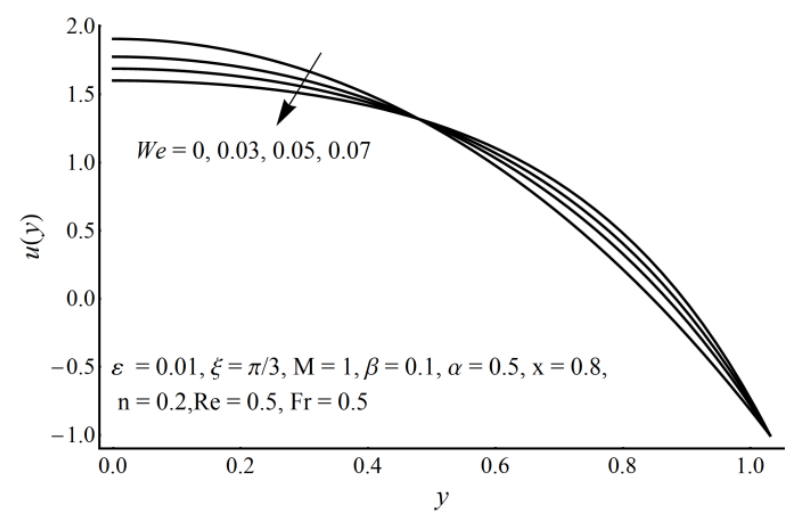

Figure 2. The velocity profile for different values of variable We. 


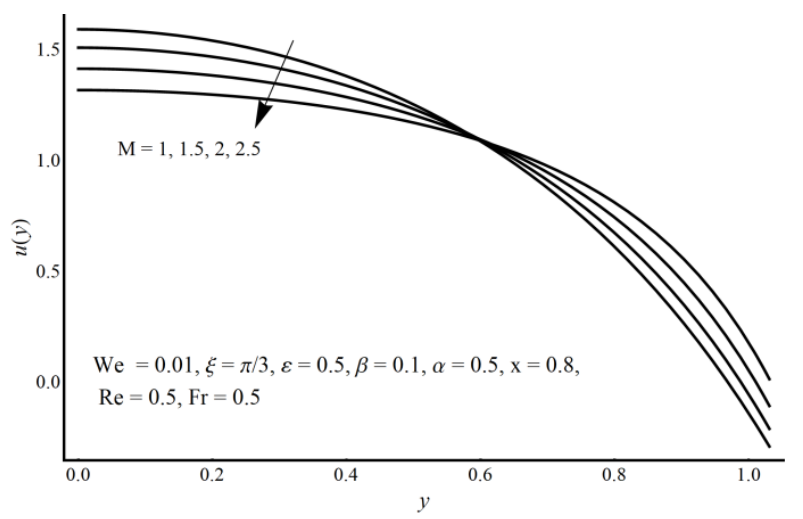

Figure 3. The velocity profile for different values of variable $M$.

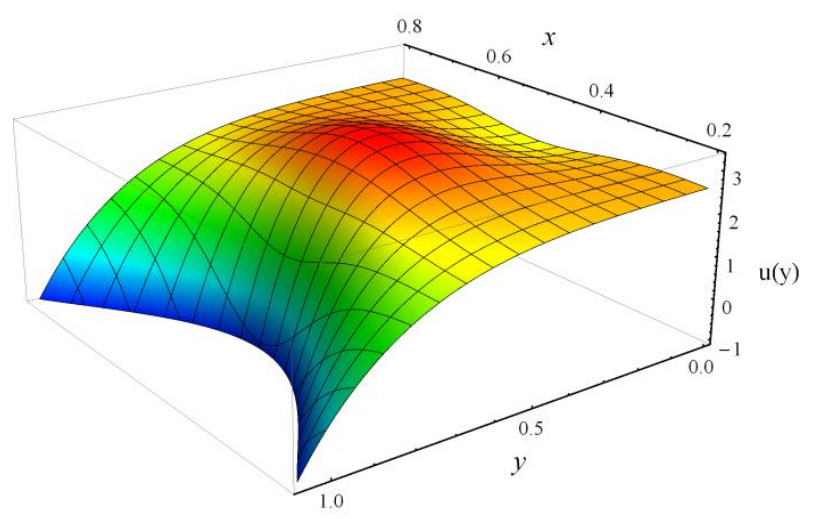

Figure 4. A $3 \mathrm{D}$ velocity profile when $M=1, n=\alpha=0.2, W e^{2}=0.03, \varepsilon=\beta=0.1, \xi=\pi / 3, F r=0.5$.

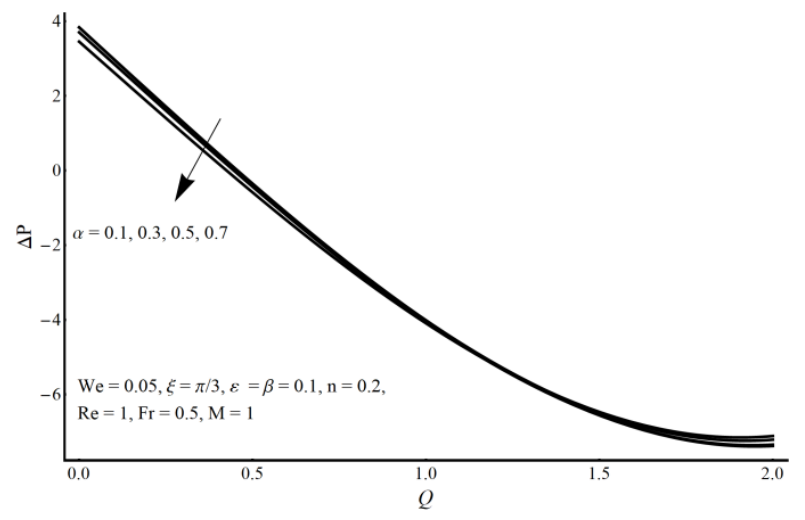

Figure 5. Pressure rise per wavelength at various values of $\alpha$.

From Figure 8, it is seen that the fluid temperature slightly rises by increasing the values of $\alpha$. This is because of the substantial effect of $\alpha$ on fluid flow which improves the convective process within the ciliated channel. Figure 9 shows that keeping large $\varepsilon$ cools down the fluid temperature since it decelerates the fluid velocity, which retards the convection. Moreover, the decrease in temperature is more considerable in the center as compared to the channel boundary. Figure 10 shows that increasing values of $M$ result in the cooling of the fluid temperature. Furthermore, in the channel center this decrease is more noticeable as compared to channel wall. This is an obvious conduct of the temperature, since the resistance produced by the Lorentz force is more substantial at the channel center. A three-dimensional depiction of the temperature profile against the space variables $x$ and $y$ is illustrated in Figure 11. It is clear from the figure that, in the contracted part of the channel, the temperature is elevated, as compared to the wider part of channel. This is due to the intensified 
fluid friction effect in the presence of good heat convection in the contracted part, which augments the internal heat as well.

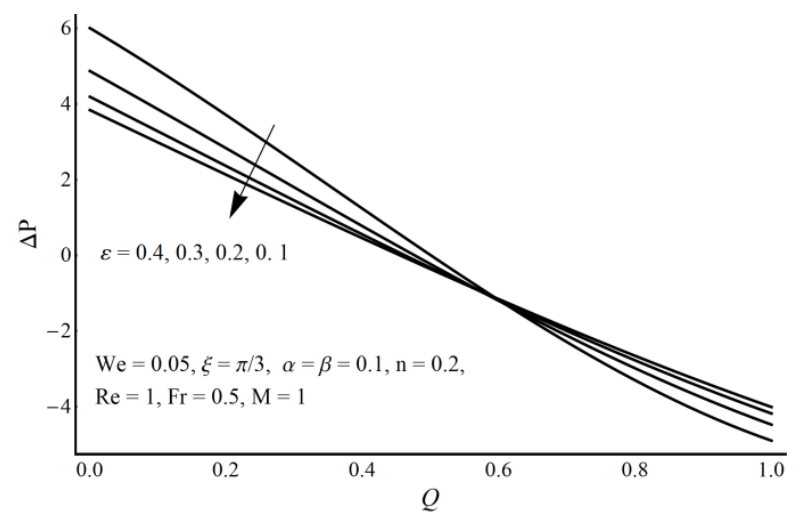

Figure 6. Pressure rise per wavelength at various values of $\varepsilon$.

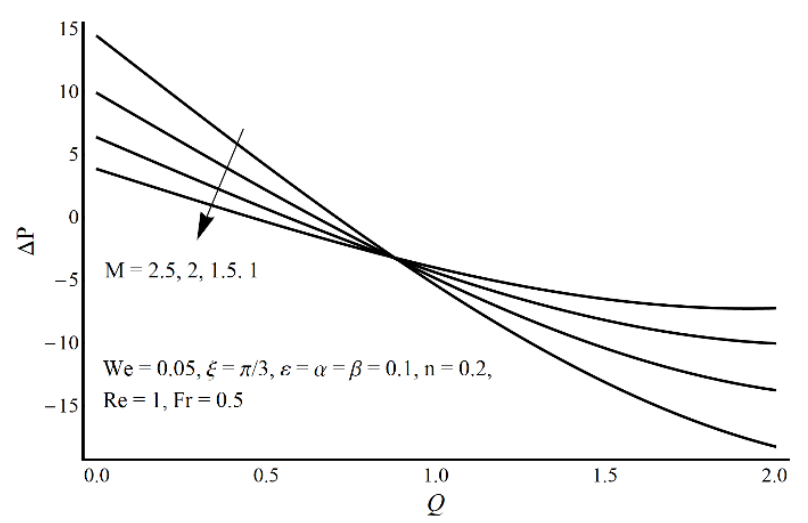

Figure 7. Pressure rise per wavelength at various values of $M$.

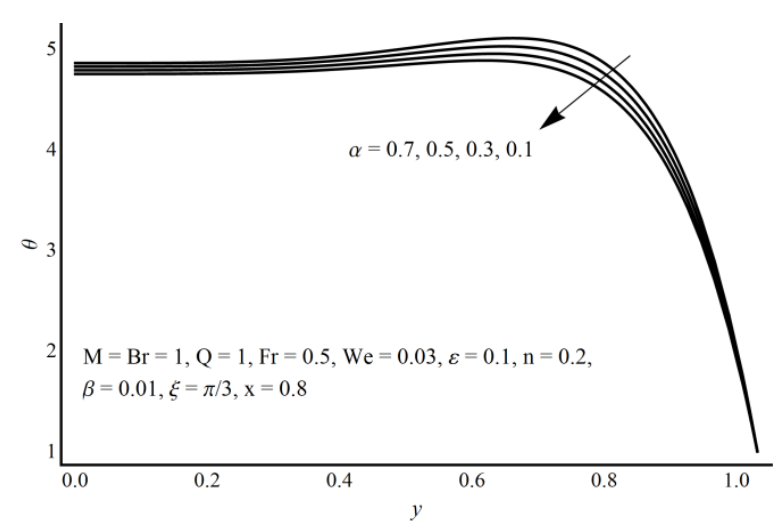

Figure 8. Temperature profile for different values of $\alpha$. 


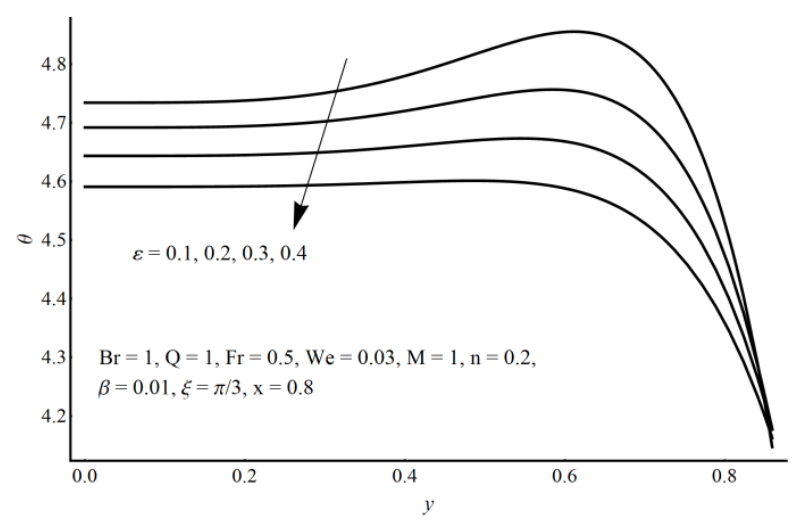

Figure 9. Temperature profile for different values of $\varepsilon$.

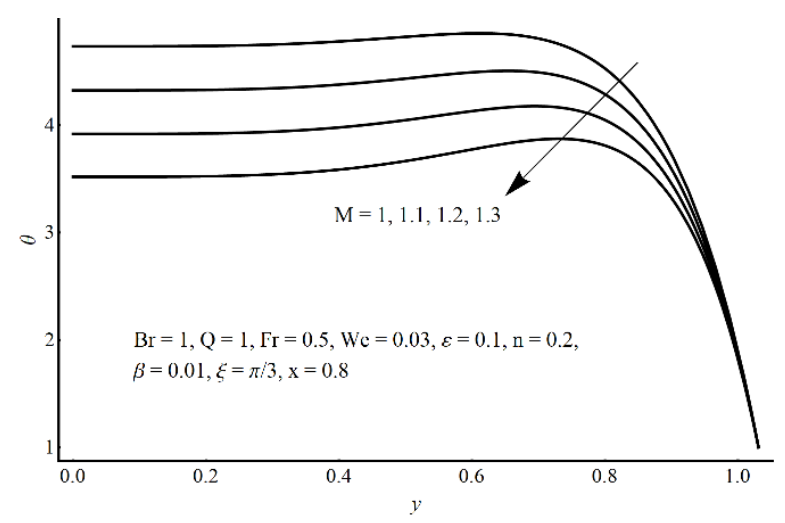

Figure 10. Temperature profile for different values of $M$.

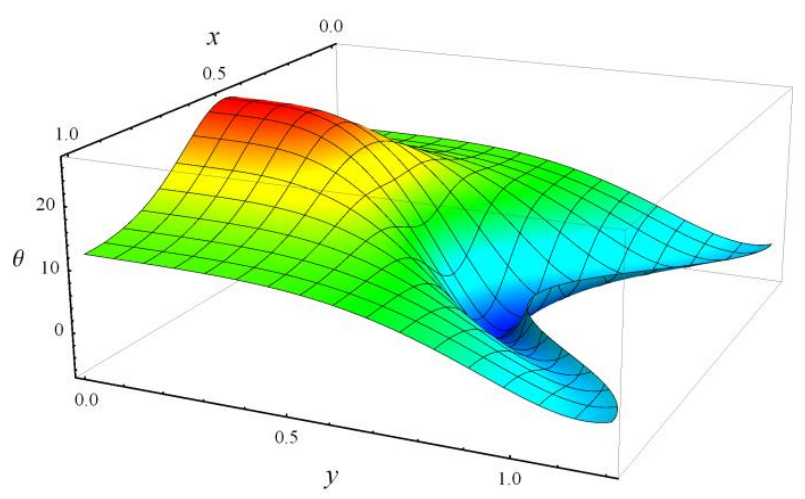

Figure 11. A $3 \mathrm{D}$ temperature profile fixing $M=B r=1, n=\varepsilon=0.2, \alpha=0.1, W e=0.01, \beta=F r=0.5, \xi=\pi / 3$.

From Figure 12, contour plots for entropy lines indicate that entropy generation increases when a larger value of $\alpha$ is considered. From Figure 13, it is clear that by increasing the value of $W e$, the entropy generation number reduces. It is also observed that entropy is significant near the ciliated heated wall but invisible at the channel center. Figure 14 shows that the cilia length also reduce the entropy production in the channel. This might be because large cilia put hinderance to the flow and reduce the drag and thus the frictional entropy significantly. Figure 15 reveals that there is a decrease in the entropy production as the Hartmann number increases. However, this increase in the entropy production is due to the increase in the fluid frictional forces. This is also verified from the graph of the Bejan number against the Hartmann number (see for instance Figure 16). The Bejan number is plotted against the Weissenberg number and the cilia length parameter in Figures 17 and 18, respectively. The figures indicate that cilia length supports heat transfer irreversibility; however, the Weissenberg number helps in fluid friction irreversibility. 

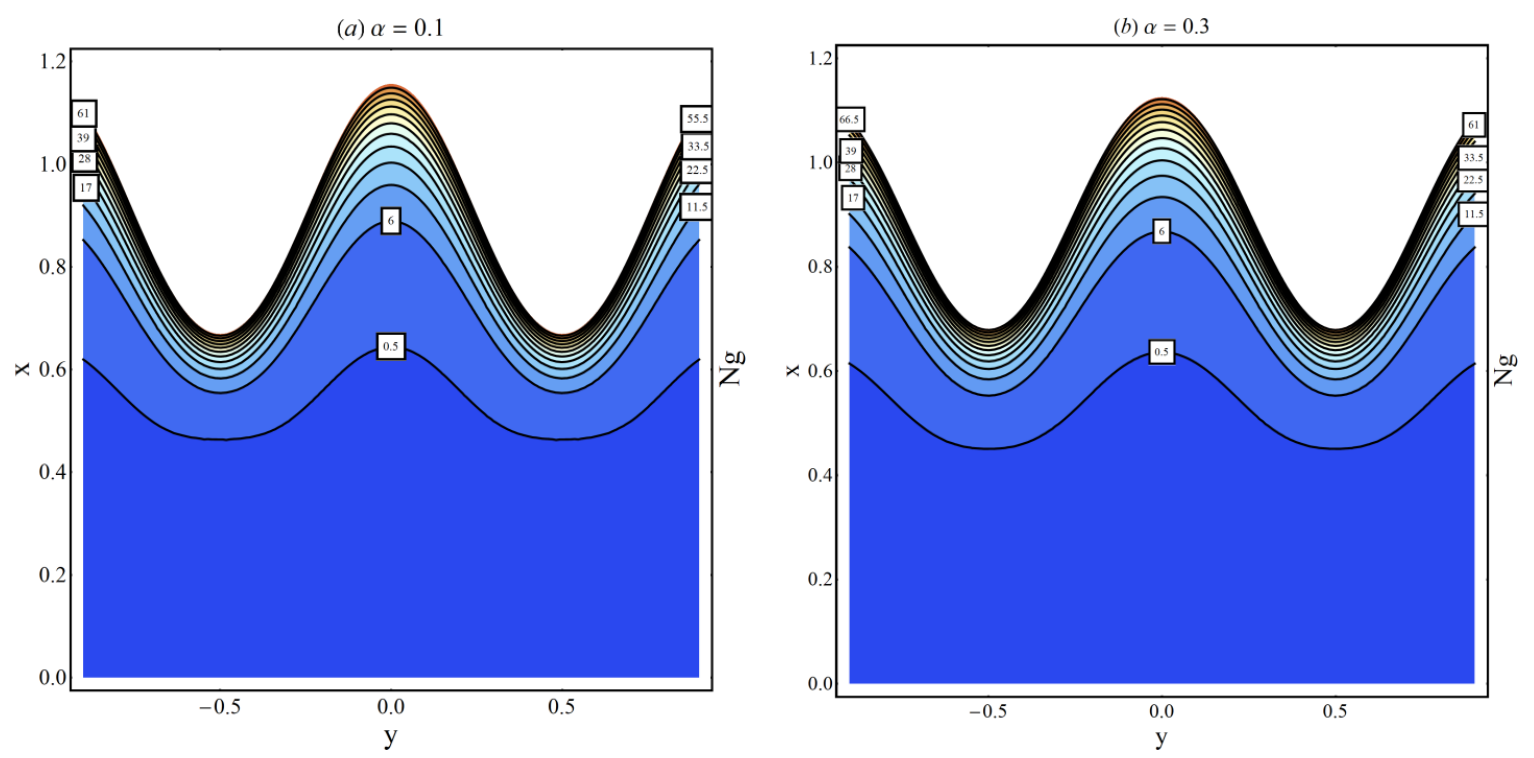

Figure 12. Entropy lines at two different $\alpha$ values: (a) $\alpha=0.1$ and (b) $\alpha=0.3$.
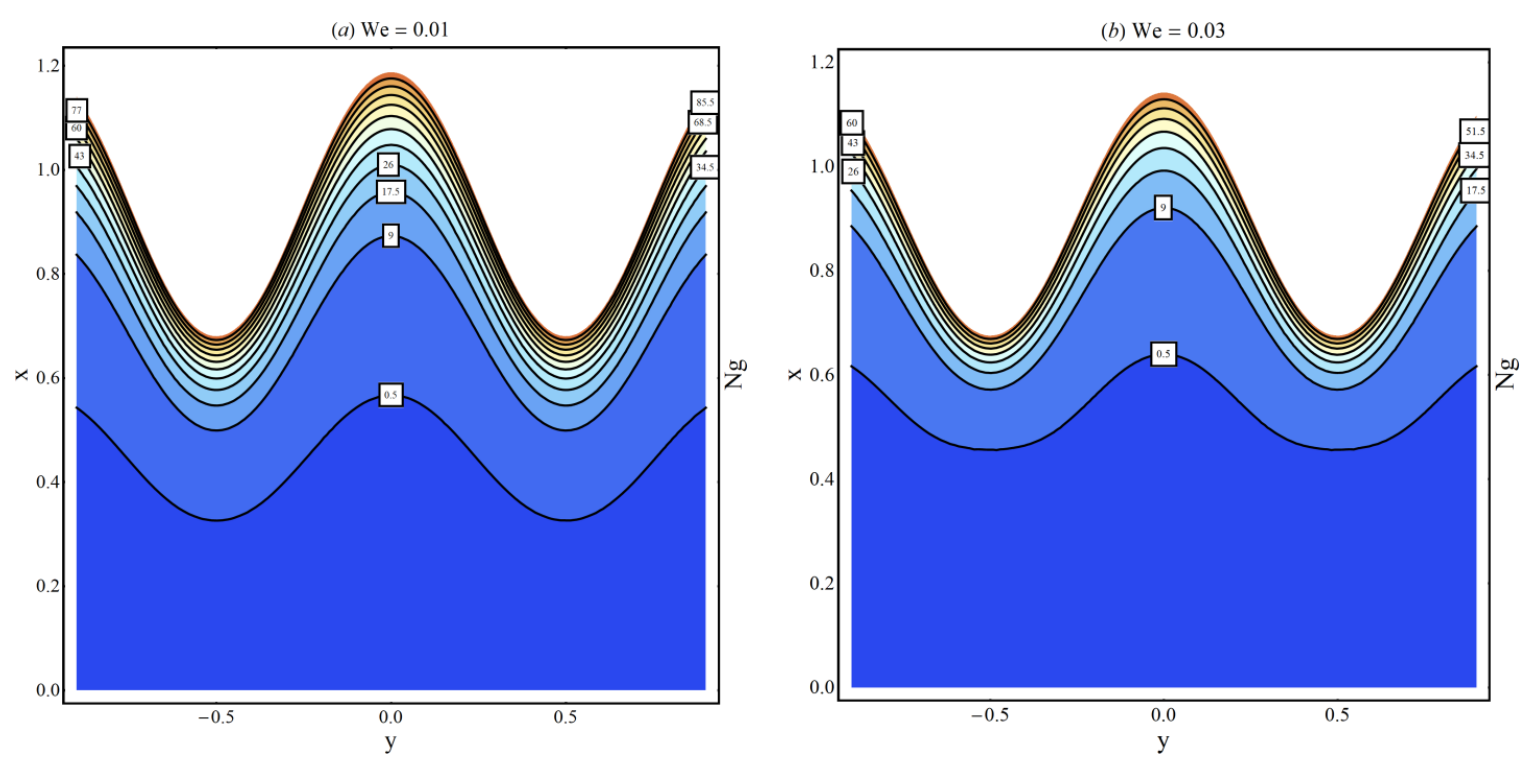

Figure 13. Entropy lines at two different $W e$ : (a) $W e=0.01$ and (b) $W e=0.03$ 

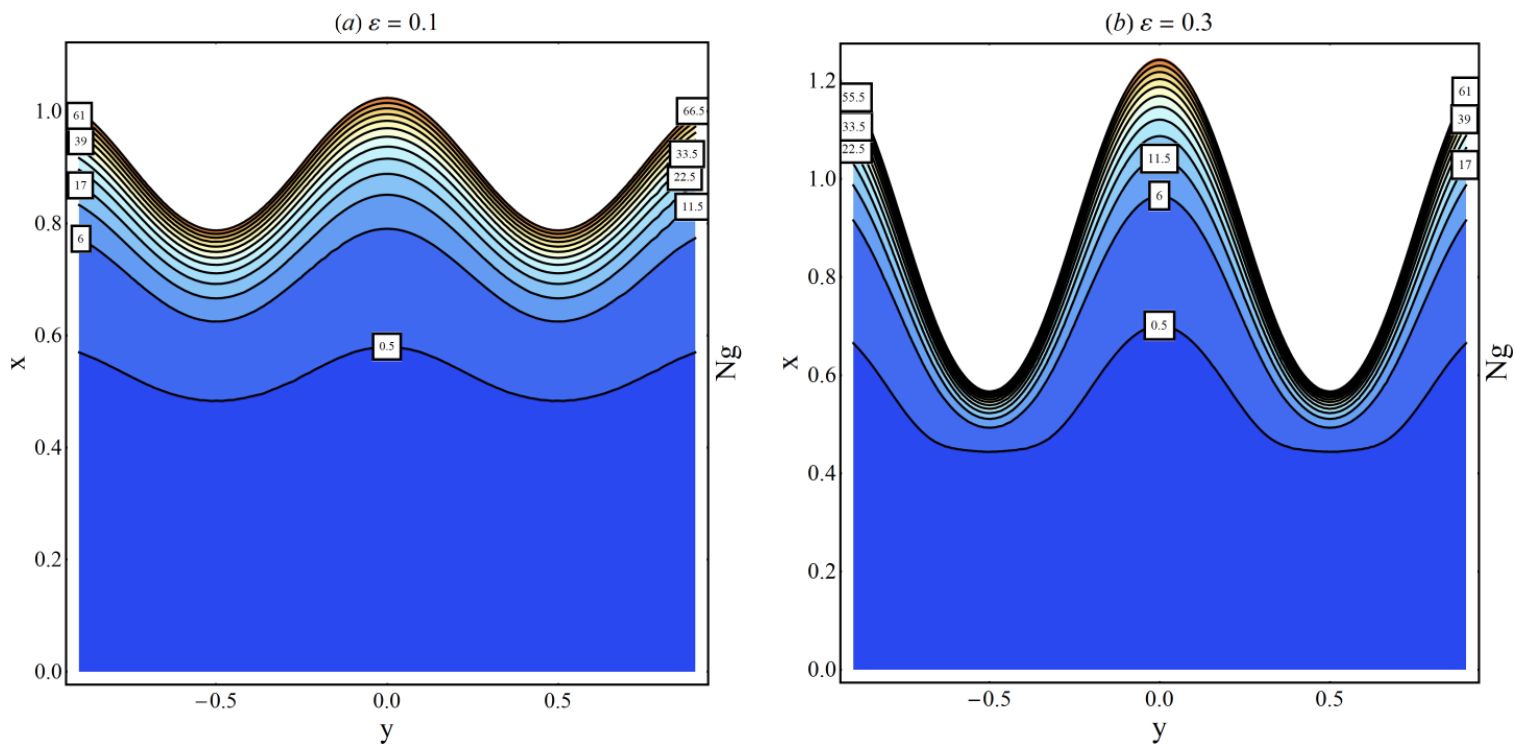

Figure 14. Entropy lines at two different values of $\varepsilon$ : (a) $\varepsilon=0.1$ and (b) $\varepsilon=0.3$
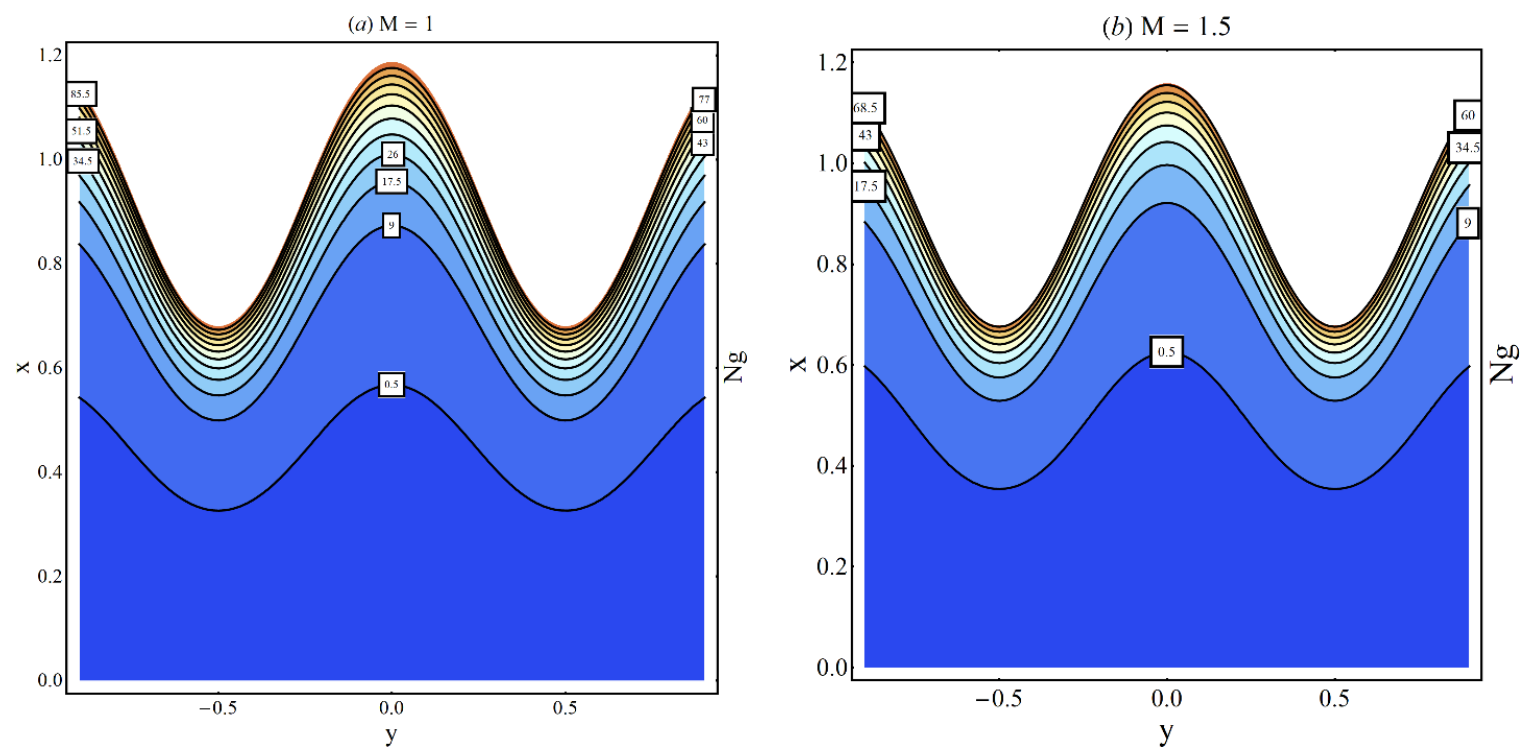

Figure 15. Entropy lines at two different values of $M$ : (a) $M=1$ and (b) $M=1.5$.

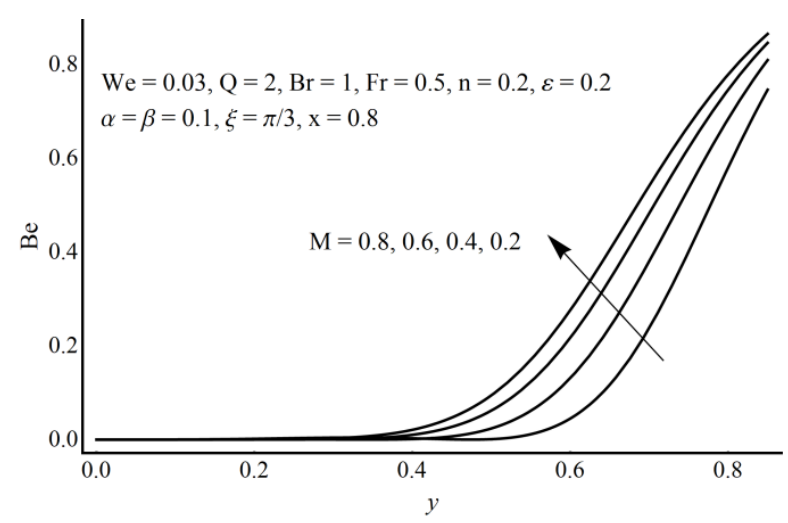

Figure 16. Effect of $M$ on the Bejan number. 


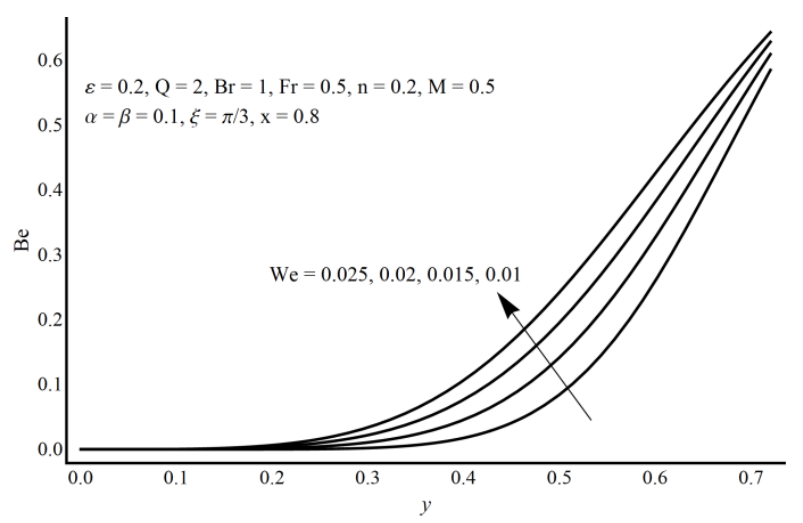

Figure 17. Effect of We on the Bejan number.

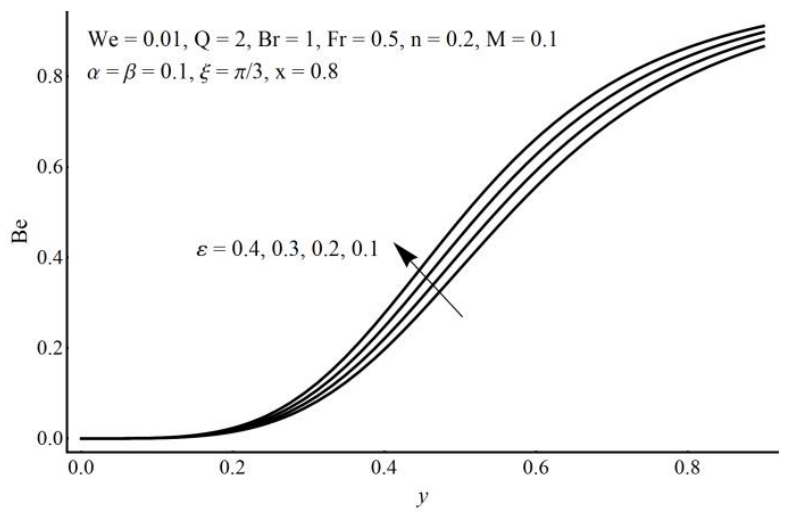

Figure 18. Effect of $\varepsilon$ on the Bejan number.

Figures 19-21 demonstrate a noteworthy trend of pumping ciliary flow, well-known in the literature and called trapping. It is developed by the internal circular motion of fluid making a bolus locked by streamlines of propulsive waves. This enclosed bolus is shoved ahead with the support of a metachronal wave (power and recovery strokes). Figure 19 shows that the trapped bolus reduces in size when large values of $M$ are taken into consideration. From Figures 20 and 21, it is concluded that the locked bolus expands in size for higher values of $\varepsilon$ and $\alpha$.

(a) $\mathrm{M}=0.5$

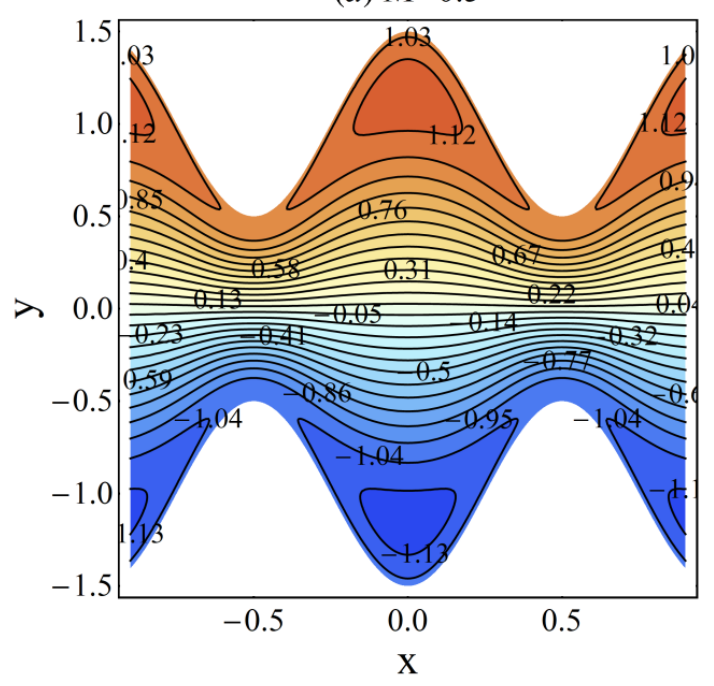

(b) $\mathrm{M}=1.5$

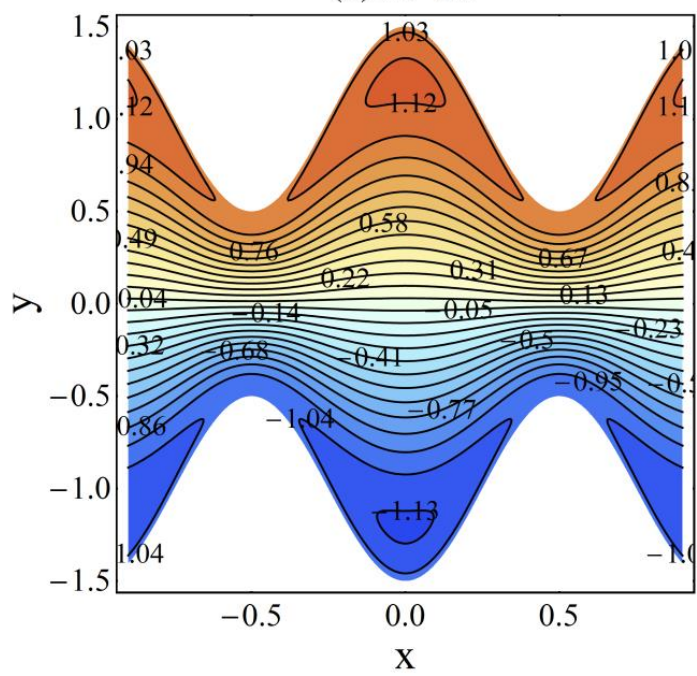

Figure 19. Streamlines at different $\mathrm{M}$ when $\mathrm{Fr}=1, n=\varepsilon=0.2, \alpha=0.1, W e^{2}=0.01, \beta=0.5, \xi=\pi / 3$, $F r=0.5:$ (a) $M=0.5$ and (b) $M=1.5$. 

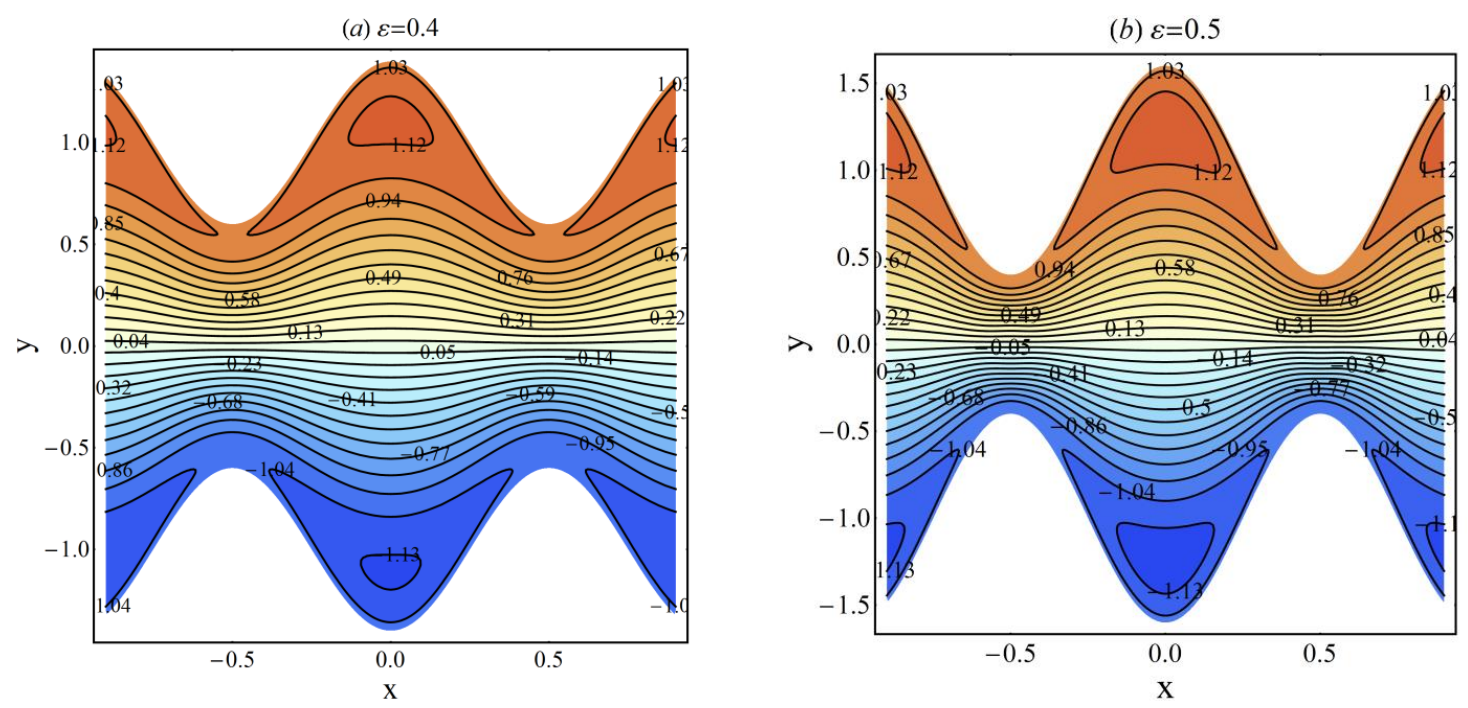

Figure 20. Streamlines at different $\varepsilon$ when $F r=1, n=0.2, \alpha=0.1, W e^{2}=0.01, \beta=0.5, \xi=\pi / 3, F r=M=0.5$ : (a) $\varepsilon=0.4$ and (b) $\varepsilon=0.5$.
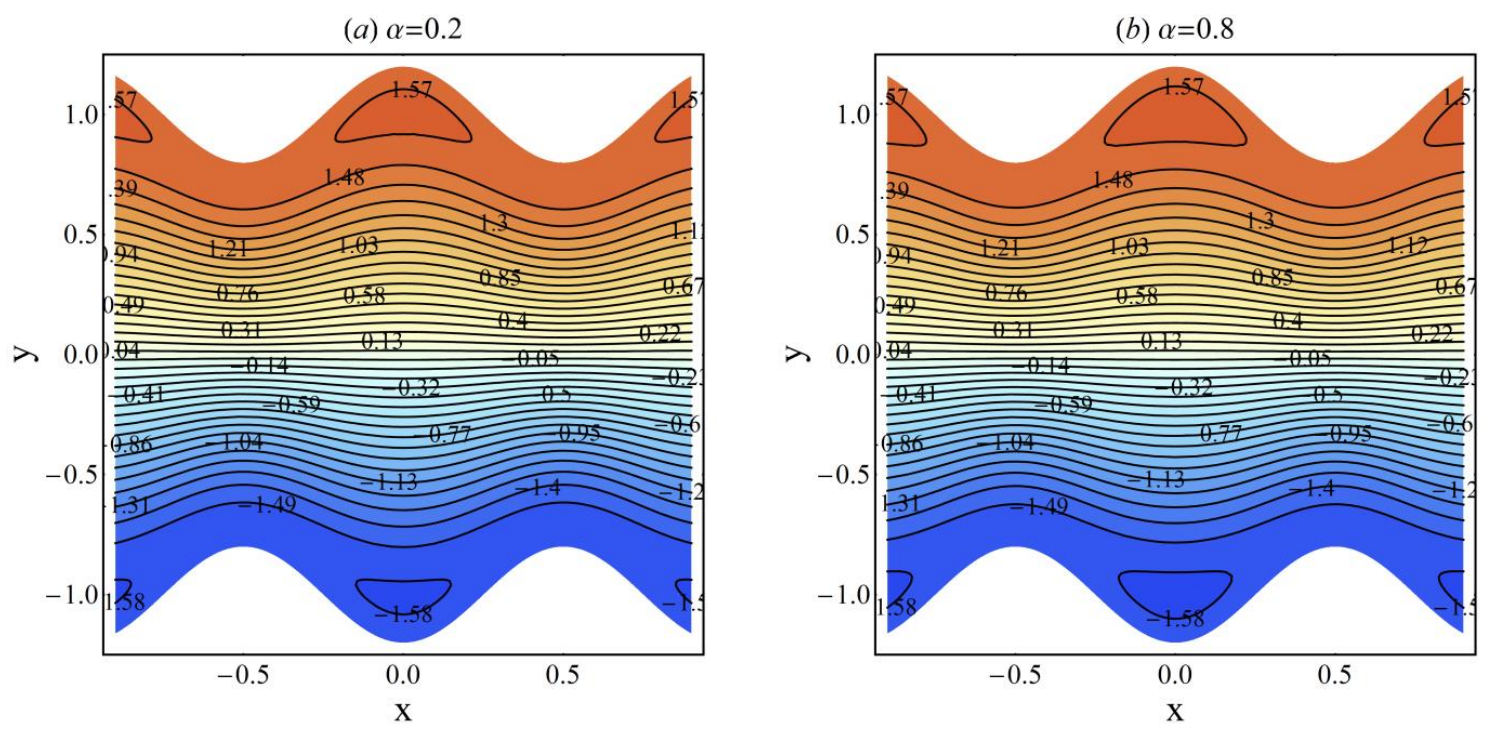

Figure 21. Streamlines at different $\alpha$ when $F r=1, n=0.2, \varepsilon=0.2, W e^{2}=0.01, \beta=0.5, \xi=\pi / 3, F r=M=0.5$ : (a) $\alpha=0.2$ and (b) $\alpha=0.8$.

\section{Conclusions}

In the present work, a thermodynamic analysis has been presented for the pumping flow of hydromagnetic Carreau fluid in an inclined symmetric channel lined with cilia. The flow is propelled by rhythmic (metachronal) waves produced by the beating of cilia. The governing equations are derived in the wave frame of reference and are solved by the regular perturbation technique. The results are verified with a numerical method. The important concluding remarks of the present study are compiled below:

- The large values of $M, \varepsilon$ and We correspond to low axial velocity at the channel center but augment the velocity near the ciliated wall.

- The pressure rise per metachronal wavelength is an increasing function of $\varepsilon$ and $M$ in the pumping region and a decreasing function of these parameters in the augmented pumping region.

- The pressure rise per wavelength is boosted by increasing $\alpha$ in the augmented pumping region but a completely reversed situation is seen in the pumping region. 
- Fluid temperature rises when large values of $\alpha$ and small values of $M$ and $\varepsilon$ are taken into consideration.

- The fluid friction irreversibility is supported by high Weissenberg and Hartmann numbers; however, heat transfer irreversibility increases with cilia length.

- The overall entropy of the system increases with larger values of $\alpha$ and smaller values $W e, \varepsilon$ and $M$.

- The size of the locked bolus decreases for higher values of $M$ and smaller values of $\varepsilon$ and $\alpha$.

Author Contributions: Conceptualization, N.S. and S.M.; Methodology, N.S.; Software, N.S.; Validation, S.M; Formal Analysis, S.M.; investigation, N.S and S.M.; Resources, N.S.; Data Curation, N.S.; Writing-Original Draft Preparation, N.S.; Writing-Review and Editing, S.M.; Visualization, S.M.; Supervision, N.S.; Project Administration, N.S.; Funding Acquisition, N.S. All authors have read and agreed to the published version of the manuscript.

Funding: This research received no external funding.

Acknowledgments: The authors would like to acknowledge the support provided by the Deanship of Research (DR) at the Prince Mohammad Bin Fahd University for funding this work.

Conflicts of Interest: The authors declare no conflict of interest.

\section{Nomenclature}

\section{Latin symbols}

\section{$a$}

Be

Br

C

$C_{p}$

Ec

F

Fr

H

h

h

$\kappa$

M

$N_{G}$

$N s_{a v g}$

$n$

Ṕ

$p$

Pr

$Q$

Re

$S_{\text {gen }}^{\prime \prime \prime}$

$S_{G 0}$

$t$

'́

$T_{0}$

$T_{1}$

(Ú, '́)

(u, v)

$(u, v)$ mean channel width

Bejan number

Brinkman number

wave speed

specific heat

Eckert number

dimensionless flow rate

Froude number

height of wall in fixed frame

height of wall in moving frame

dimensionless height of wall

thermal conductivity

Hartmann number

entropy generation number

average entropy number

power-law index

pressure in fixed frame

dimensionless pressure

Prandtl number

mean flow rate

Reynolds number

entropy generation rate

characteristic entropy generation

Time variable

temperature profile

temperature of endoscope

wall temperature

velocity components in fixed frame

velocity components in moving frame

dimensionless velocity components 


$\begin{array}{ll}\text { We } & \text { Weissenberg number } \\ (\dot{X}, \bar{Y}) & \text { coordinates in fixed frame of reference } \\ (\dot{x}, \hat{y}) & \text { coordinates in moving frame of reference } \\ (x, y) & \text { dimensionless coordinate system } \\ X_{0} & \text { indicated location of the particle } \\ \text { Greek symbols } & \\ \alpha & \text { measure of eccentricity } \\ \beta & \text { wave number } \\ \varepsilon & \text { cilia length } \\ \rho & \text { density of fluid } \\ \lambda & \text { wavelength } \\ \theta & \text { dimensionless temperature field } \\ \mu & \text { variable viscosity } \\ \mu_{0} & \text { zero shear rate viscosity } \\ \sigma & \text { electrical conductivity } \\ \Phi & \text { irreversibility distribution ratio } \\ \Delta p_{\lambda} & \text { pressure rise per wavelength } \\ \Delta T & \text { temperature difference } \\ \tau & \text { dimensionless temperature difference } \\ \xi & \text { angle of inclination of channel }\end{array}$

\section{References}

1. Pablo, J.L.; DeCaen, P.G.; Clapham, D.E. Progress in ciliary ion channel physiology. J. Gen. Physiol. 2016, 149, 37-41. [CrossRef] [PubMed]

2. Eddy, C.A.; Pauerstein, C.J. Anatomy and physiology of the fallopian tube. Clin. Obstet. Gynecol. 1980, 4, 1177-1193. [CrossRef] [PubMed]

3. Ghazal, S.; Makarov, J.K.; de Jonge, C.J. Egg transport and fertilization. Glob. Libr. Womens Med. $2014,2014$. [CrossRef]

4. Lehti, M.S.; Sironen, A. Formation and function of sperm tail structures in association with sperm motility defects. Biol. Reprod. 2017, 97, 522-536. [CrossRef]

5. Wheway, G.; Nazlamova, L.; Hancock, J.T. Signaling through the Primary Cilium. Front. Cell Dev. Biol. 2018, 6, 8. [CrossRef]

6. Brennen, C. Oscillating-boundary layer theory for ciliary propulsion. J. Fluid Mech. 1974, 65, 799-824. [CrossRef]

7. Qiu, T.; Lee, T.; Mark, A.G.; Morozov, K.I.; Münster, R.; Mierka, O.; Turek, S.; Leshansky, A.M.; Fischer, P. Swimming by reciprocal motion at low Reynolds number. Nat. Commun. 2014, 5, 1-8. [CrossRef]

8. Eytan, O.; Elad, D. Analysis of intra-uterine fluid motion induced by uterine contractions. Bull. Math. Biol. 1999, 61, 221-238. [CrossRef]

9. Farooq, A.A.; Tripathi, D.; Elnaqeeb, T. On the propulsion of micropolar fluid inside a channel due to ciliary induced metachronal wave. Appl. Math. Comput. 2019, 347, 225-235. [CrossRef]

10. Farooq, A.A.; Siddiqui, A.M. Mathematical model for the ciliary-induced transport of seminal liquids through the ductuli efferentes. Int. J. Biomath. 2017, 10, 1750031. [CrossRef]

11. Ponalagusamy, R. Mathematical analysis of flow of non-Newtonian fluid due to metachronal beating of cilia in a tube and its physiological applications. Appl. Math. Comput. 2018, 337, 545-561. [CrossRef]

12. Ezzat, M.; Djahanbakhch, O.; Arian, S.; Carr, B.R. Tubal transport of gametes and embryos: A review of physiology and pathophysiology. J. Assist. Reprod. Genet. 2014, 10, 1337-1347. [CrossRef] [PubMed]

13. Stud, V.K.; Sephon, G.S.; Mishra, R.K. Pumping action on blood flow by a magnetic field. Bull. Math. Biol. 1977, 39, 385-390.

14. Maqbool, K.; Shaheen, S.; Mann, A.B. Exact solution of cilia induced flow of a Jeffrey fluid in an inclined tube. Springerplus 2016, 5, 1379. [CrossRef]

15. Hayat, T.; Saleem, N.; Mesloub, S.; Ali, N. Magnetohydrodynamic Flow of a Carreau Fluid in a Channel with Different Wave Forms. Z. Naturforch. A 2011, 66, 215-222. [CrossRef] 
16. Ramesh, K.; Tripathi, D.; Beg, O.A. Cilia-assisted hydromagnetic pumping of biorheological couple stress fluids. J. Propul. Power 2019, 8, 221-233. [CrossRef]

17. Saleem, N.; Akram, S.; Afzal, F.; Aly, E.H.; Hussain, A. Impact of velocity second slip and inclined Magnetic field on peristaltic flow coating with Jeffrey fluid in tapered channel. Coatings 2020, 10, 30. [CrossRef]

18. Shi, L.; Hu, Y.; He, Y. Magnetocontrollable convective heat transfer of nanofluid through a straight tube. Appl. Therm. Eng. 2019, 162, 114220. [CrossRef]

19. Riaz, A.; Alolaiyan, H.; Razaq, A. Convective Heat Transfer and Magnetohydrodynamics across a Peristaltic Channel Coated with Nonlinear Nanofluid. Coatings 2019, 9, 816. [CrossRef]

20. Akram, S.; Aly, E.H.; Afzal, F.; Nadeem, S. Effect of the variable viscosity on the peristaltic flow of Newtonian fluid coated with magnetic field: Application of adomian decomposition method for endoscope. Coatings 2019, 9, 524. [CrossRef]

21. Bejan, A. A study of entropy generation in fundamental convective heat transfer. J. Heat Transf. Trans. ASME 1979, 101, 718-725. [CrossRef]

22. Bejan, A. Second-law analysis in heat transfer and thermal design. In Advances in Heat Transfer; Hartnett, J.P., Irvine, T.F., Eds.; Elsevier: Amsterdam, The Netherlands, 1982; Volume 15, pp. 1-58.

23. Butt, A.S.; Ali, A.; Munawar, S. Slip effects on entropy generation in MHD flow over a stretching surface in the presence of thermal radiation. Int. J. Exergy 2013, 13, 1-20. [CrossRef]

24. Adesanya, S.O.; Makinde, O.D. Thermodynamic analysis for a third grade fluid through a vertical channel with internal heat generation. J. Hydrodyn. 2015, 27, 264-272. [CrossRef]

25. Makinde, O.D. Second law analysis for variable viscosity hydromagnetic boundary layer flow with thermal radiation and Newtonian heating. Entropy 2011, 13, 1446-1464. [CrossRef]

26. Munawar, S.; Ali, A.; Mehmood, A. Thermal analysis of the flow over an oscillatory stretching cylinder. Phys. Scr. 2012, 86, 065401. [CrossRef]

27. Chamkha, A.J.; Selimefendigil, F. MHD free convection and entropy generation in a corrugated cavity filled with a porous medium saturated with nanofluids. Entropy 2018, 20, 846. [CrossRef]

28. Pour, M.S.; Nassab, S.A.G. Numerical investigation of forced laminar convection flow of nanofluids over a backward facing step under bleeding condition. J. Mech. 2012, 28, N7-N12. [CrossRef]

29. Abu-Nada, E. Numerical prediction of entropy generation in separated flows. Entropy 2005, 7, $234-252$. [CrossRef]

30. Souidi, F.; Ayachi, K.; Benyahia, N. Entropy generation rate for a peristaltic pump. J. Non Equilib. Thermodyn. 2009, 34, 171-194. [CrossRef]

31. Akbar, N.S. Entropy generation and energy conversion rate for the peristaltic flow in a tube with magnetic field. Energy 2015, 82, 23-30. [CrossRef]

32. Munawar, S.; Saleem, N.; Aboura, K. Second law analysis in the peristaltic flow of variable viscosity fluid. Int. J. Exergy 2016, 20, 170-185.

33. Saleem, N. Entropy production in peristaltic flow of a space dependent viscosity fluid in asymmetric channel. Therm. Sci. 2018, 22, 2909-2918. [CrossRef]

34. Hayat, T.; Saleem, N.; Ali, N. Peristaltic flow of a Carreau fluid in a channel with different wave forms. Numer. Methods Partial. Differ. Equ. 2010, 26, 519-534. [CrossRef]

35. Ali, N.; Hayat, T. Peristaltic motion of a Carreau fluid in an asymmetric channel. Appl. Math. Comput. 2007, 193, 535-552. [CrossRef]

36. Nadeem, S.; Akram, S.; Hayat, T.; Hendi, A.A. Peristaltic flow of a Carreau fluid in a rectangular duct. J. Fluids Eng. 2012, 134, 041201. [CrossRef]

37. Bejan, A. Second law analysis in heat transfer. Energy 1980, 5, 720-732. [CrossRef]

38. Munawar, S.; Saleem, N. Thermal analysis of an Eyring-Powell fluid flow through a constricted channel. Therm. Sci. 2018, 308. [CrossRef]

(C) 2020 by the authors. Licensee MDPI, Basel, Switzerland. This article is an open access article distributed under the terms and conditions of the Creative Commons Attribution (CC BY) license (http://creativecommons.org/licenses/by/4.0/). 